\title{
A Mobile System to Improve Quality of Life Via Energy Balance in Breast Cancer Survivors (BENECA mHealth): Prospective Test-Retest Quasiexperimental Feasibility Study
}

Mario Lozano-Lozano ${ }^{1,2,3,4}$, MSc, OT; Irene Cantarero-Villanueva ${ }^{1,2,3,4}, \mathrm{PhD}$; Lydia Martin-Martin ${ }^{1,2,3,4}$, PhD; Noelia Galiano-Castillo $^{1,2,3,4}$, PhD; Maria-José Sanchez ${ }^{3,5,6}$, PhD; Carolina Fernández-Lao ${ }^{1,2,3,4}, \mathrm{PhD}$; Paula Postigo-Martin ${ }^{1,2,4}$, MSc; Manuel Arroyo-Morales ${ }^{1,2,3,4}, \mathrm{MD}, \mathrm{PhD}$

\footnotetext{
${ }^{1}$ Department of Physical Therapy, Faculty of Health Sciences, University of Granada, Granada, Spain

${ }^{2}$ Sport and Health University Research Institute, Granada, Spain

${ }^{3}$ Biohealth Research Institute in Granada, Granada, Spain

${ }^{4}$ Cuidate-Support Unit for Oncology Patients, Granada, Spain

${ }^{5}$ Andalusian School of Public Health, Granada, Spain

${ }^{6}$ Consortium for Biomedical Research in Epidemiology and Public Health, Madrid, Spain
}

\section{Corresponding Author:}

Irene Cantarero-Villanueva, $\mathrm{PhD}$

Department of Physical Therapy

Faculty of Health Sciences

University of Granada

Avda de la Ilustración, 60

Granada,

Spain

Phone: 34958248764

Email: irenecantarero@ugr.es

\begin{abstract}
Background: Energy balance is defined as the difference between energy expenditure and energy intake. The current state of knowledge supports the need to better integrate mechanistic approaches through effective studies of energy balance in the cancer population because of an observed significant lack of adherence to healthy lifestyle recommendations. To stimulate changes in breast cancer survivors' lifestyles based on energy balance, our group developed the BENECA (Energy Balance on Cancer) mHealth app. BENECA has been previously validated as a reliable energy balance monitoring system.

Objective: Based on our previous results, the goal of this study was to investigate the feasibility of BENECA mHealth in an ecological clinical setting with breast cancer survivors, by studying (1) its feasibility and (2) pretest-posttest differences with regard to breast cancer survivor lifestyles, quality of life (QoL), and physical activity (PA) motivation.

Methods: Eighty breast cancer survivors diagnosed with stage I to IIIA and with a body mass index over $25 \mathrm{~kg} / \mathrm{m} 2$ were enrolled in this prospective test-retest quasi-experimental study. Patients used BENECA mHealth for 8 weeks and were assessed at baseline and the postintervention period. Feasibility main outcomes included percentage of adoption, usage, and attrition; user app quality perception measured with the Mobile App Rating Scale (MARS); satisfaction with the Net Promoter Score (NPS); and barriers and facilitators of its use. Clinical main outcomes included measuring QoL with the European Organization for Research and Treatment of Cancer QoL Questionnaire Core 30 (EORT QLQ-C30), PA assessment with accelerometry, PA motivation measure with a Spanish self-efficacy scale for physical activity (EAF), and body composition with dual-energy x-ray absorptiometry. Statistical tests (using paired-sample $t$ tests) and Kaplan-Meier survival curves were analyzed.

Results: BENECA was considered feasible by the breast cancer survivors in terms of use (76\%, 58/76), adoption $(69 \%, 80 / 116)$, and satisfaction (positive NPS). The app quality score did not make it one of the best-rated apps (mean 3.71, SD 0.47 points out of 5). BENECA mHealth improved the QoL of participants (global health mean difference [MD] 12.83, 95\% CI 8.95-16.71, $\mathrm{P}<.001$ ), and EAF score (global MD 36.99, 95\% CI 25.52-48.46, P<.001), daily moderate-to-vigorous PA (MD 7.38, $95 \%$ CI $0.39-14.37, \mathrm{P}=.04$ ), and reduced body weight (MD $-1.42,95 \% \mathrm{CI}-1.97$ to $-0.87, \mathrm{P}<.001$ ).
\end{abstract}


Conclusions: BENECA mHealth can be considered feasible in a real clinical context to promote behavioral changes in the lifestyles of breast cancer survivors, but it needs to be enhanced to improve user satisfaction with use and functionality. This study highlights the importance of the use of mobile apps based on energy balance and how the QoL of breast cancer survivors can be improved via monitoring.

(JMIR Mhealth Uhealth 2019;7(6):e14136) doi: $\underline{10.2196 / 14136}$

\section{KEYWORDS}

mHealth; energy balance; monitoring; breast cancer; survivors; quality of life

\section{Introduction}

There is a direct relationship between energy imbalance and an increased risk of not only multiple cancers but also cancer mortality, and a worsening of the effects of the disease [1-3]. Energy balance is defined as the difference between energy expenditure and energy intake [4]. Energy intake that exceeds energy expenditure is the main driver of weight gain; thus, balancing both helps weight maintenance [5].

A panel of experts from the International Agency for Research on Cancer and the World Cancer Research Fund agreed that 16 types of cancer are probably associated with one of the more relevant consequences of energy imbalance, excess fat accumulation in the body, making obesity the second leading cause of cancer worldwide [1,6]. Moreover, since the first decade of the 2000s, the scientific evidence on the benefits of physical activity (PA) in the quality of life (QoL) of cancer survivors (known as "oncological exercise") has grown exponentially, generating dozens of systematic reviews, several international guidelines, and the recommendation to include programs of exercise in cancer survivors care [7]. Dietary and exercise interventions can alter the energy imbalance associated with cancer and potentially decrease the QoL of cancer survivorship [5]. However, the literature shows that despite strong evidence of this association, an insurmountable barrier prevails between "what needs to be done" and "what patients really do," observing a significant lack of adherence to the preceding interventions [1].

In today's progressively technical world, the use of mobile apps in smart devices has become the norm. In the same way, patients increasingly use therapeutic mobile apps related to some form of cancer treatment [8]. More than 2500 mobile apps are defined as apps related to cancer, but this relationship is peripheral or based on unproven claims, such as apps for yoga and naturopathy that claim to help prevent or even cure cancer [9]. In $2017,15 \%$ of studies conducted worldwide were aimed at digital health, with $75 \%$ of these studies being conducted in the United States [9]. Recently, 539 apps were considered in a systematic review, which concluded that the effectiveness of most of them had not been validated scientifically $[8,10]$. Duman-Lubberding and colleagues [11] have developed Oncokompas, an eHealth app to facilitate access to supportive cancer care and monitor cancer patients' QoL [12], specifically in the case of breast cancer [13]. Another study by Gietema and colleagues [14] assessed the feasibility of the Runkeeper app to improve the level of PA of cancer patients. They concluded that there is a need to increase research in the area. Different studies and meta-analyses of cancer patients show the benefits of mHealth, which include reducing fatigue or pain $[15,16]$, distance PA programs with inconclusive results for and against [17-19], the use of social networks by patients of some types of cancer to improve QoL [20], and monitoring of symptoms $[21,22]$. However, none of these studies refers to monitoring and providing high-quality research feedback to restore the energy balance in cancer patients. The only references found in this field were in healthy populations [23,24], children and adolescents [25], pregnant women [26], hospitalized patients [27], and cardiac surgery [28] and diabetes [29] patients. Furthermore, monitoring using globally extended systems, such as Fitbit wristbands, is being questioned [30]. A recent systematic review of 67 studies concluded that, except for the measurement of steps in adults, there are a limited number of situations in which these devices provide accurate measurement for use in research [30].

In an attempt to stimulate changes in breast cancer survivors' lifestyles based on energy balance, we developed the BENECA mHealth app: Energy Balance on Cancer [31,32]. BENECA mHealth aims to monitor the energy expenditure and energy intake of breast cancer survivors and provide instantaneous, simple, and clear feedback on the users' energy balance, along with recommendations on how to improve it. This strategy was based on a recent systematic review of behavior change techniques for increasing PA in cancer survivors [33], as well as another study carried out by Hillier et al [34], who developed a Web-based program to assess energy balance in healthy adults. The first essential step, to develop and validate our tool, was to ensure the reliability of the BENECA mHealth monitoring system. The results of our previous study showed that it is a direct, rapid, and consistent evaluation system [32]. Based on these results, the goal of this study was to investigate the feasibility of BENECA mHealth in an ecological setting with a population of cancer survivors after they are discharged from their oncology treatment.

This involved studying the adoption of the app, its usage, user app quality perception, and the barriers and facilitators of its use. In addition, we gained insight into pretest-posttest differences with regard to breast cancer survivors' lifestyles, QoL, and PA motivation. This investigation was based on the hypothesis that using the BENECA mHealth app for 8 weeks would help increase the motivation of breast cancer survivors to adhere to healthier lifestyles, thereby improving their QoL. 


\section{Methods}

\section{Study Design and Patient Recruitment}

A prospective test-retest quasi-experimental study was carried out with 80 breast cancer survivors. The breast cancer survivors were selected based on the following eligibility criteria: (1) breast cancer stage I, II, or IIIA, (2) 30 to 75 years old, (3) body mass index (BMI) over $25 \mathrm{~kg} / \mathrm{m}^{2}$, (4) user-level skills for app management, and (5) completed the adjuvant treatment at least 6 months before being included in the study. Eligible participants were excluded if they had mental or physical health conditions that prevented them from walking and/or participating in the assessment or if they did not sign the informed consent form. In addition, participants had to have access to a mobile device or tablet with an internet connection and an Android operating system. The research team loaned out two devices in cases where this was not possible or the operating system was incompatible with the app. All participants were recruited through the oncology unit from the University Hospital Complex of Granada, Spain, after being informed about the study and being referred by their respective oncologist. All eligible participants were contacted via telephone, screened using the inclusion and exclusion criteria, and if they were interested in participating, cited for the baseline assessment.

This study was approved by the ethics committee of the Andalusian Health Service (FIS, PI14-01627; Granada, Spain) and it was performed in accordance with the Helsinki Declaration for biomedical research (14/2017) [35]. Participants completed informed consent forms before the assessment.

\section{BENECA mHealth}

The CUIDATE research group developed the Energy Balance on Cancer (BENECA) mHealth app to monitor and provide feedback to breast cancer survivors on healthy eating and PA. A description of the BENECA mHealth System [31,36] and a reliability study for the same [32] were previously published. After the baseline assessment was performed, a member of the research group downloaded the app on a patient's mobile phone and taught them how to use it. The patient then had to prove that she understood the instructions by using the app in the presence of the researcher. Patients had to use BENECA mHealth for 8 weeks during the study. Physical activity (duration and intensity) and diet (food and drink intake) data were recorded via the app (self-recorded). Intake was recorded using a dietary record questionnaire; BENECA is structured with six consumption times. On each day, for each period, users report all food and beverages consumed. For PA, BENECA incorporated the Minnesota Leisure-time Physical Activity Questionnaire. Patients had to record intensity and duration of activities each day; BENECA only recorded those activities with a duration of at least 10 minutes. Using this information, the app sent a notification to the user of their daily energy balance, offering recommendations on diet and PA, which were based on the guidelines of the World Cancer Research Fund International, the strategies for PA and diet in patients with cancer from the American College of Sports Medicine [37], and the recommendations of the American Cancer Society [38]. Users receive a straightforward daily notification if there has been an energy imbalance; any difficulties in handling the app were resolved via calls and text messages between the researcher and patient (Multimedia Appendix 1). BENECA had been developed based on the theories of learning, Goal-Setting Theory, and Social Cognitive Theory to include techniques such as reinforcement, facilitation, self-monitoring, goal setting, feedback on performance, and reviewing goals, which have demonstrated to be promising in increasing PA in different populations $[33,39]$. A video tutorial was made available to the patients to review the use of the app.

\section{Outcome Measures}

Patient demographic and clinical data were obtained at the beginning of the study using a study-specific survey. Baseline data were gathered at the start of the study and again after 8 weeks of using BENECA mHealth. The outcomes measured are presented subsequently.

\section{Feasibility of Main Outcomes}

BENECA mHealth was considered feasible for use by breast cancer survivors as long as it met the following criteria, established based on previous studies with eHealth apps $[11,13,40,41]$ : adoption and usage rate over $50 \%$, a positive Net Promoter Score (NPS), and a Mobile App Rating Scale (MARS) score of up to 3.73 out of 5 .

\section{Adoption, Usage, and Attrition}

The adoption rate was the percentage of the number of breast cancer survivors that agreed to participate in the study and completed the initial assessment, demonstrating the intention to use BENECA mHealth, out of the total number invited to participate in the study. The usage rate is the percentage of breast cancer survivors that used BENECA mHealth, which was determined through the logging data of the app. Both the adoption and usage rates were calculated based on the methods used in a previously published study [13]. The attrition rate is the percentage of breast cancer survivors that stopped using BENECA mHealth and did not use it again, as per Eysenbach's definition [42]. To assess the safety of the process, any adverse effects reported by the patients were recorded through a patient's daily diary.

\section{BENECA mHealth Quality}

The MARS was used to assess the quality of BENECA mHealth. The MARS is composed of 23 items grouped into different sections: engagement, functionality, aesthetics, and information quality (with which the overall average score of the scale is obtained). There are also two optional sections: subjective quality (with four items) and app-specific quality (with six items). Each item was assessed independently based on a Likert scale from 1 (inadequate) to 5 (excellent), and the mean score was calculated for each section. This scale has been validated and has proven to be simple, objective, and reliable to assess the quality of mHealth apps [43]. Similarly, the NPS was used to measure satisfaction based on responses to the following question: How likely are you to recommend BENECA mHealth to other breast cancer survivors? The responses were recorded using an 11-point Likert scale in which 0 indicates "not likely" and 10 indicates "very likely." The percentage of detractors (those whose scores were from 0 to 6 ) and promoters (those 
whose scores were from 9 to 10) were calculated, and each group was given a score between -100 and 100 . A positive score is considered good; a negative score is considered bad [44]. This methodology has been used as a predictor of growth and an indicator of customer satisfaction in for-profit industries, and it provides insight into the client experience in nonprofit health care settings [45].

\section{Barriers and Facilitators}

After the participants used BENECA mHealth for 8 weeks and completed the corresponding assessment, a trained member of the research team interviewed each participant using a standardized set of interview questions based on a previous study [13]. This interview focused on three main elements: overall experience with BENECA mHealth, congruence between expectations and reality with BENECA mHealth, and the perception and added value of BENECA mHealth. For cases in which the app was no longer used, the participants were asked about their reasons for not using the app and the preferences or needs that would prompt them to use it. Each interview was read several times and transcribed by the same researcher, and the barriers and facilitators reported by the breast cancer survivors were synthesized [46].

\section{Main Clinical Outcomes}

\section{Quality of Life}

The European Organization for Research and Treatment of Cancer QoL Questionnaire Core 30 (EORTC QLQ-C30) version 3.0 was used to assess the QoL of the participants. This questionnaire is intended to measure general aspects of QoL specific to cancer patients. It contains five functional scales (physical, role, cognitive, emotional, and social functioning), a global health status scale, and symptom scales of fatigue, nausea and vomiting, pain, dyspnea, insomnia, appetite loss, constipation, diarrhea, and financial problems. It is scored using a four-point Likert scale (from 1="not at all" to 4="very much") and the raw scores are transformed into a 0 to 100 scale. The higher the score on the functional scales, the better the QoL, but the higher the score on the symptom scales, the poorer the QoL $[47,48]$.

\section{Self-Efficacy and Motivation in Relation to Physical Activity}

A Spanish self-efficacy scale for physical activity (EAF) was used to measure the self-efficacy and motivation of the participants to engage in PA and incorporate it into their daily activities. It consists of three domains: scheduled physical exercise, PA in daily life activities, and walking, which determine a person's perception of their abilities to engage in PA (self-efficacy for PA) [49].

\section{Physical Activity}

Data on PA and the sedentary lifestyle of the breast cancer survivors were collected using accelerometry based on a previously published protocol of use and analysis [50]. A preprogrammed triaxial accelerometer (ActiGraph GT3X+, Pensacola, FL, USA) was used by each patient for eight consecutive days. The participants received a questionnaire diary and an instruction sheet on how to use the device. Only the records of more than 4 days and of at least 10 hours per day were included in the analysis.

\section{Body Composition}

Dual-energy x-ray absorptiometry (Discovery DXA densitometer from Hologic, QDR $4500 \mathrm{~W}$ ) was used for assessing BMI, the percentage of fat mass, and bone mineral density, as previously used for breast cancer patients [51] in accordance with protocol of use [52]. The height and weight of the participants were also measured at baseline as well as hip and waist circumferences.

\section{Statistical Analysis}

All analyses were performed using SPSS Statistics version 24 (IBM Corp, Armonk, NY, USA). Statistical significance was assumed when $P<.05$. The logging data from BENECA mHealth were obtained on request from the computer engineers responsible for the development of the app.

First, descriptive measures were used to report the data on adoption, use, attrition, and quality, as well as to report on the clinical and anthropometric variables of the participants. A Kaplan-Meier survival curve was used to visually examine the survival curve of the entire cohort to determine the attrition. In the analysis, an "app survivor" was defined as a breast cancer survivor that maintained logging practices using BENECA mHealth until at least 3 days before the last day of the experimental period. Those defined under "app death" were those who missed five consecutive daily loggings (based on a previous study [53]). A Kaplan-Meier estimator with right-censored data was used. This type of data was used because it best fit our study results. As most of the breast cancer survivors "survived" until the end of the experimental period, we do not know how long they would have continued using BENECA mHealth after this period. Then, a Cox proportional hazard model was used to examine if age, marital status, and employment had any effect on the attrition.

Second, to assess the pretest-posttest differences in the main outcomes, an analysis of paired-sample $t$ tests was used and, when appropriate, Wilcoxon signed rank tests were conducted. Moreover, the effect size (ES) estimate was determined and interpreted using Cohen's guidelines of $0.1=$ small effect, $0.3=$ medium effect, and $0.5=$ large effect.

Third, to assess differences between "users" and "nonusers" and the patients' perception of BENECA mHealth quality, a Mann-Whitney test was used for categorizing the breast cancer survivors according to the cut-off used in the survival analysis. A simple linear regression was used to examine the influence of age on the perception of BENECA mHealth quality.

Our data contained a few missing values $(5 \%, 4 / 80$ of the total number of cases), but these can be considered random and inconsequential [54]. Hence, no multiple imputation method was necessary (casewise deletion was used). 


\section{Results}

\section{Demographic Characteristics}

The baseline demographic and clinical characteristics of the participants (mean age 51.80, SD 8.64 years) are presented in Table 1. Of the 80 breast cancer survivors, 50 (62\%) were married, $31(38 \%)$ had a higher education, and $40(50 \%)$ were diagnosed with stage II breast cancer, followed in frequency by stage IIIA $(28 / 80,35 \%)$. All participants received instructions on how to use BENECA mHealth to monitor energy intake and expenditure. Four participants were unable to be assessed postintervention (dropouts); three were not assessed due to changes in their health status unrelated to the study, and one decided to discontinue.

Table 1. Participant demographics $(\mathrm{N}=80)$.

\begin{tabular}{|c|c|}
\hline Variables & Participants \\
\hline Age (years), mean (SD) & $51.80(8.64)$ \\
\hline Body mass index, mean (SD) & $29.11(4.77)$ \\
\hline \multicolumn{2}{|l|}{ Marital status, n (\%) } \\
\hline Single & $16(20)$ \\
\hline Married & $50(63)$ \\
\hline Divorced & $10(13)$ \\
\hline Other & $4(5)$ \\
\hline \multicolumn{2}{|l|}{ Education, n (\%) } \\
\hline No education & $1(1)$ \\
\hline Primary studies & $23(29)$ \\
\hline Secondary studies & $25(31)$ \\
\hline Higher education & $31(39)$ \\
\hline \multicolumn{2}{|l|}{ Employment, n (\%) } \\
\hline Homemaker & $18(22)$ \\
\hline Employee & $32(40)$ \\
\hline Low & $10(13)$ \\
\hline Unemployed by the disease & $20(25)$ \\
\hline \multicolumn{2}{|l|}{ Cancer stage, n (\%) } \\
\hline I & $10(13)$ \\
\hline II & $40(51)$ \\
\hline IIIA & $28(36)$ \\
\hline \multicolumn{2}{|l|}{ Surgery, n (\%) } \\
\hline Lumpectomy & $24(30)$ \\
\hline Quadrantectomy & $13(16)$ \\
\hline Unilateral mastectomy & $27(34)$ \\
\hline Bilateral mastectomy & $16(20)$ \\
\hline \multicolumn{2}{|l|}{ Medical treatment, $\mathrm{n}(\%)$} \\
\hline None & $6(8)$ \\
\hline Radiation therapy alone & $10(13)$ \\
\hline Chemotherapy alone & $6(8)$ \\
\hline Chemotherapy and radiation therapy & $48(60)$ \\
\hline Adjuvant chemotherapy & $7(9)$ \\
\hline Neoadjuvant chemotherapy & $3(4)$ \\
\hline
\end{tabular}




\section{Feasibility Outcomes}

\section{Adoption, Usage, and Attrition Rates}

The study design is shown in Figure 1. The adoption rate of BENECA mHealth was $69 \% ; 80$ of 116 breast cancer survivors who were invited to participate intended to use BENECA mHealth, filled the informed consent form, and were assessed at baseline. The reasons for not participating in the study included lack of interest (too busy; $n=14$ ), incompatibility of the user's mobile operating system with BENECA mHealth $(\mathrm{n}=11)$, and failed initial contact (eg, wrong phone number or no answer; $\mathrm{n}=11$ ).

The usage rate was 73\% (58/80) including dropouts and $76 \%$ (58/76) excluding dropouts. The reasons for stopping using
BENECA mHealth included technical issues, such as difficulty in finding specific foods $(n=6)$, app blocks $(n=4)$, difficulty in calculating proportions of diet registration $(n=9)$, or lack of motivation $(n=3)$. We examined attrition using the Kaplan-Meier survival curve and Cox proportional hazards model. Figure 2 illustrates the attrition curve of the study participants with their respective 95\% CIs. The curve is flat at the beginning, begins to get steeper after the first month, and flattens again with time. The Cox proportional hazards model was used to assess the differences in the survival rate using covariables that could affect this rate from the clinical point of view based on a priori knowledge. The results obtained using this model with the covariates were significant at $P=.02$; the coefficients are shown in Table 2.

Figure 1. Flow diagram of the study design. EAF: self-efficacy scale for physical activity; EORT QLQ-C30: European Organization for Research and Treatment of Cancer Quality of Life Core Questionnaire 30. ${ }^{*} \mathrm{~N}=75$ for accelerometry analyses (one broken device on preassessment).

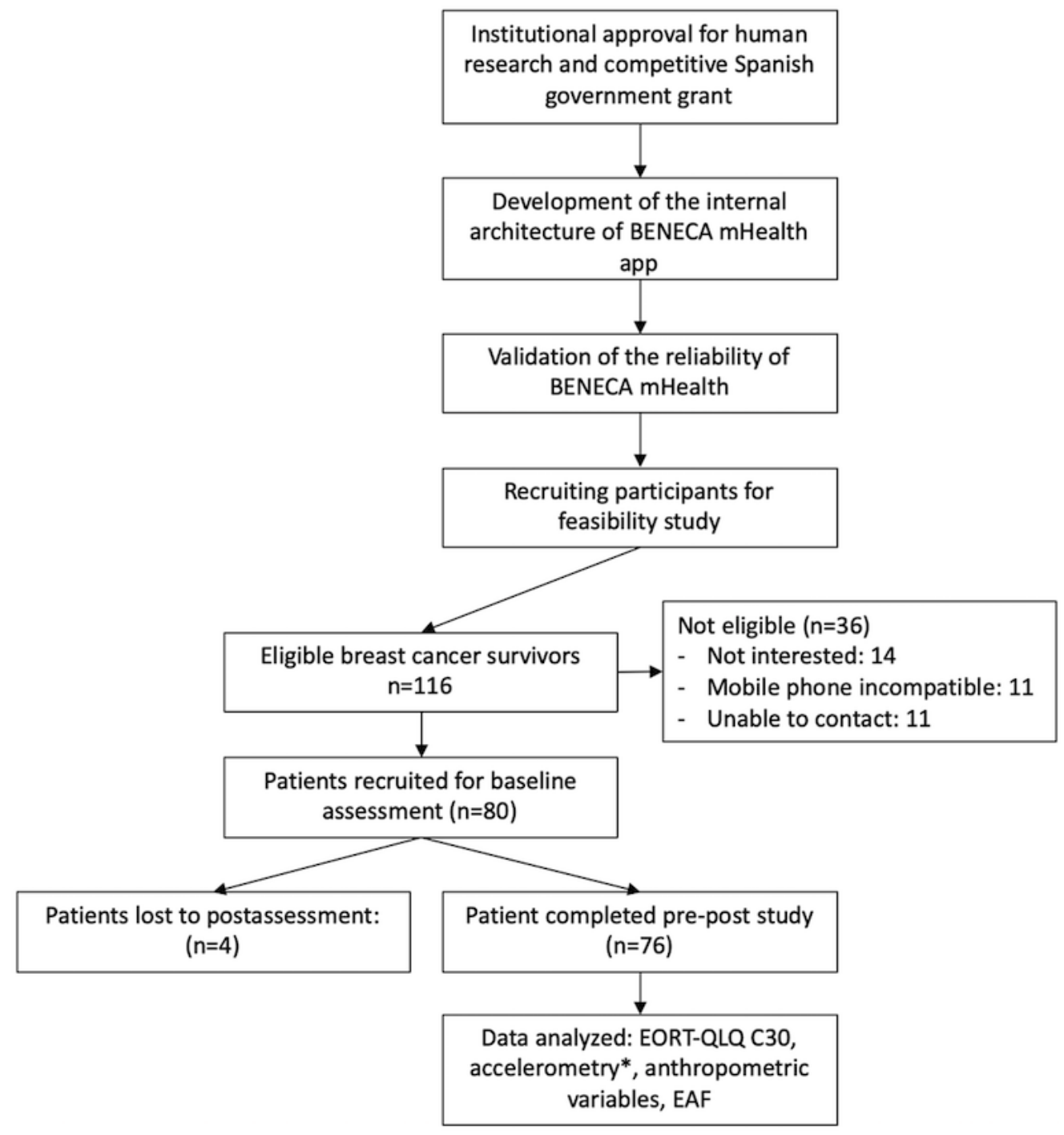


Figure 2. "Survival" of BENECA app participants as shown by a Kaplan-Meier survival curve with 95\% CIs (dashed lines).

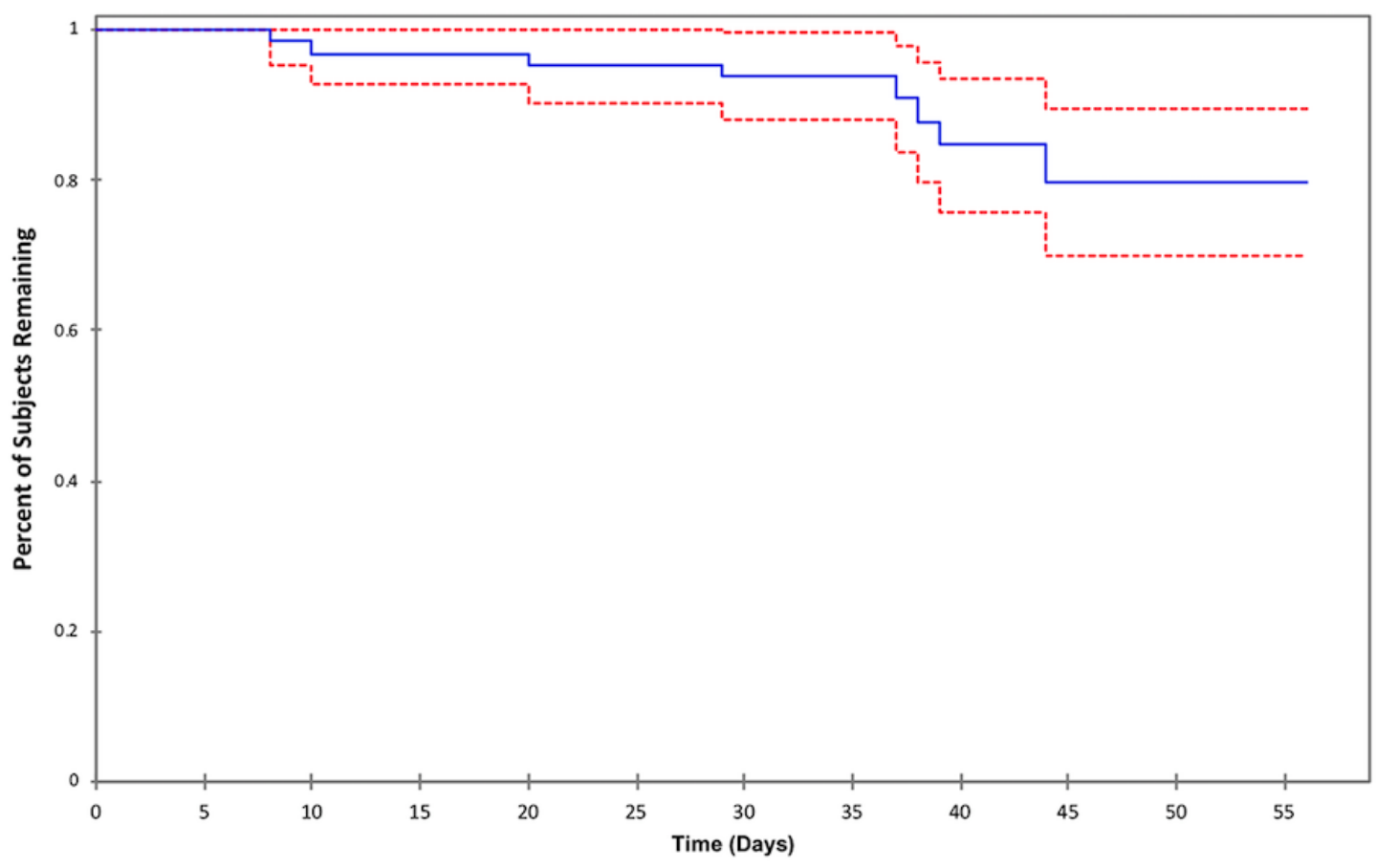

Table 2. Coefficients for the Cox proportional hazards model.

\begin{tabular}{|c|c|c|}
\hline Coefficients & Coefficient estimate $(95 \% \mathrm{CI})$ & $P$ value \\
\hline Age & $1.12(1.04-1.19)$ & .001 \\
\hline \multicolumn{3}{|l|}{ Marital status $^{\mathrm{a}}$} \\
\hline Married & $0.88(0.25-3.18)$ & .85 \\
\hline Divorced & $0.77(0.15-4.04)$ & .76 \\
\hline Other & $2.52(0.35-18.26)$ & .36 \\
\hline \multicolumn{3}{|l|}{ Employment $^{\mathbf{b}}$} \\
\hline Employee & $0.46(0.13-1.59)$ & .22 \\
\hline Low $^{c}$ & $1.12(0.27-4.62)$ & .87 \\
\hline Unemployed due to the disease & $0.46(0.12-1.67)$ & .24 \\
\hline
\end{tabular}

${ }^{a}$ Marital status reference category: single.

${ }^{b}$ Employment reference category: homemaker.

${ }^{\mathrm{c}}$ Unemployed/on leave.

\section{Patients' Perception of BENECA mHealth Quality}

The mean MARS quality score for the app was 3.71 (SD 0.47) out of 5 , and the NPS was positive (6.58 in range of -100 to $100)$, consisting of $24 \%(19 / 80)$ detractors, $30 \%(24 / 80)$ promoters, and $46 \%$ (37/80) passives. On average, the best-rated MARS category was app-specific change (mean 4.30, SD 0.37), followed by information (mean 4.22, SD 0.51 ), app subjective quality (mean 3.73 , SD 0.46 ), and functionality (mean 3.71 , SD
0.52 ). The worst-rated section was aesthetics, with a mean of 3.25 (SD 0.63). The specific scores for each section of the MARS are illustrated in Figure 3. The participants were divided according to the cut-off used in the survival analysis. It shows how the participants who used BENECA until the end of the experimental period scored higher and were statistically significant in all sections $(P<.001)$. Linear regression showed that the older the patient, the lower the app quality score (beta $=-0.29, t_{75}=-2.64, P=.01$ ). 
Figure 3. Mobile App Rating Scale (MARS) mean scoring. Data show differences between completed and noncompleted users and global mean scoring. Completed users are defined as those who used the BENECA mHealth app until study completion $(n=58)$. Noncompleted users are defined as those who stopped using the BENECA mHealth app study completion $(\mathrm{n}=22)$. ${ }^{\mathrm{P}}<.001$. UMARS: User Version of the Mobile Application Rating Scale.

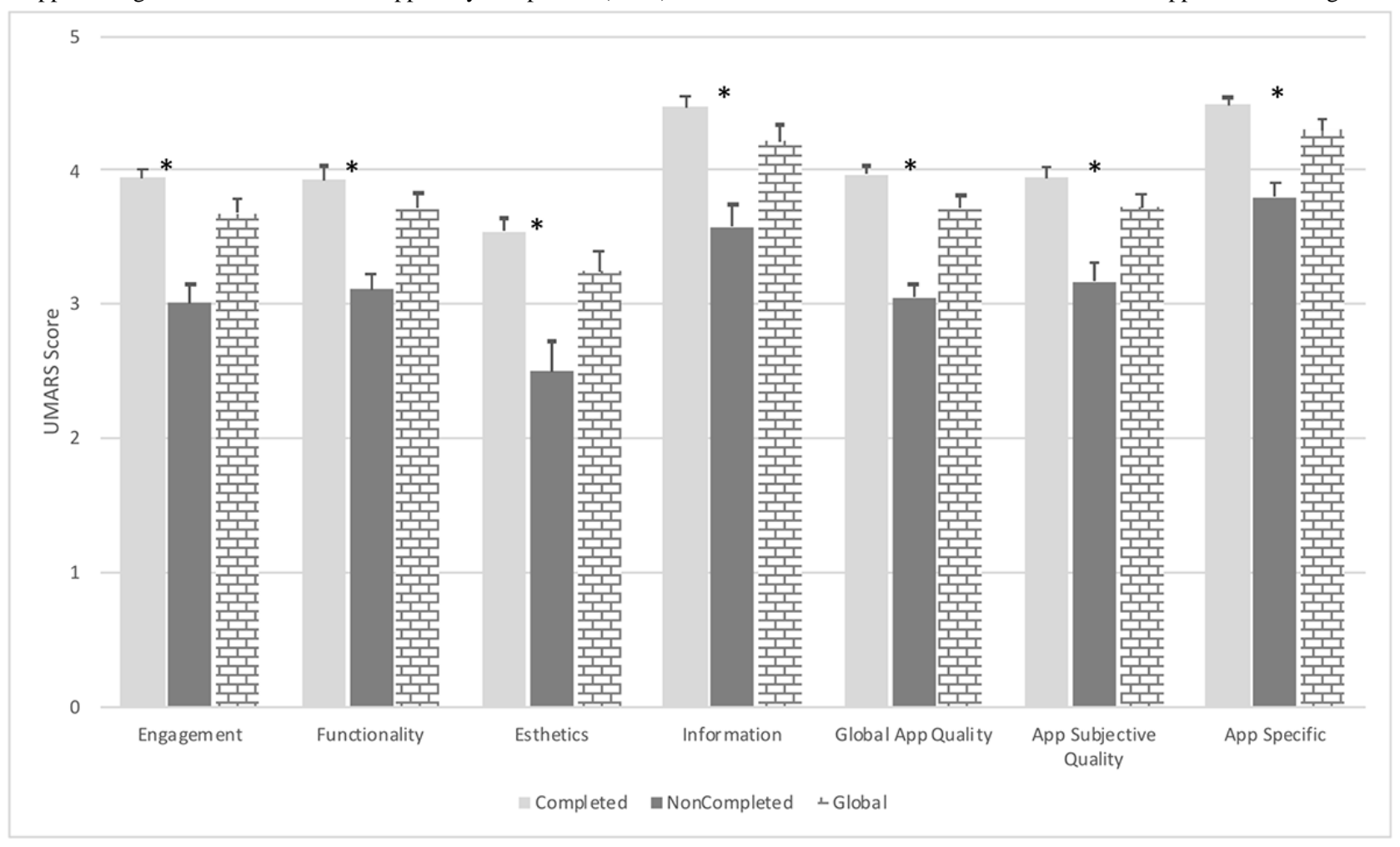

\section{Barriers and Facilitators}

In summary, seven barriers and five facilitators were quoted five times or more when the participants were interviewed. Among the barriers, the most common was "BENECA does not have some food items" followed by "difficulty at the time of introducing the intake." Among the facilitators, the most common was "BENECA provides relevant information to the patient" followed by "patient considers it important to know BENECA's feedback on energy balance." Table 3 summarizes the barriers and facilitators mentioned.

Table 3. Barriers and facilitators toward the feasibility of the BENECA mHealth app ( $\mathrm{N}=77)$.

\begin{tabular}{ll}
\hline Barriers and facilitators & $\mathrm{n}(\%)$ \\
\hline Barriers & $29(38)$ \\
Extension of BENECA & $9(12)$ \\
BENECA does not have an added value for the patient & $59(77)$ \\
BENECA does not have some food items & $8(10)$ \\
BENECA does not have some physical activities & $17(22)$ \\
BENECA feedback is limited & $42(55)$ \\
Difficulty at the time of introducing the intake & $2(3)$ \\
The patient's perception of BENECA's contribution to her health is negative & $32(42)$ \\
Facilitators & $27(35)$ \\
The usefulness of BENECA in general & $55(71)$ \\
Ease of introducing physical activity & $18(23)$ \\
Patient considers it important to know BENECA's feedback on energy balance & $51(66)$ \\
BENECA is easy to use & \\
BENECA provides relevant information to the patient &
\end{tabular}




\section{Main Clinical Outcomes}

\section{Quality of Life}

The results of the main pre-post analyses of EORT QoL C30 are shown in Table 4. Statistically significant differences were observed after the experimental period with moderate to large effects as follows: general QoL $\left(t_{75}=6.592, P<.001, d=0.87\right)$, physical functioning $\left(t_{75}=5.312, P<.001, d=0.63\right)$, emotional functioning $\left(t_{75}=2.981, P=.004, d=0.23\right)$, cognitive functioning $\left(t_{75}=5.575, P<.001, d=0.75\right)$, social functioning $\left(t_{75}=6.619\right.$, $P<.001, d=0.82)$, fatigue $\left(t_{75}=-6.003, P<.001, d=0.85\right)$, pain $\left(t_{75}=-2.017, P=.047, d=0.23\right)$, dyspnea $\left(t_{75}=-5.190, P<.001\right.$, $d=0.61)$, and insomnia $\left(t_{75}=-2.905, P=.005, d=0.32\right)$. An improvement in the scores of all these items, as well as a reduction in some symptoms, was observed after 2 months of using BENECA mHealth.

Table 4. Within-group pre-post effects on mean quality of life scores on the European Organization for Research and Treatment of Cancer Quality of Life Core Questionnaire 30 (EORTC QLQ-C30).

\begin{tabular}{|c|c|c|c|c|}
\hline \multirow[t]{2}{*}{ EORT QLQ-C30 variable } & \multicolumn{2}{|c|}{ Study group, mean (SD) } & \multirow[t]{2}{*}{ Mean difference $(95 \% \mathrm{CI})$} & \multirow[t]{2}{*}{$P$ value $^{\mathrm{a}}$} \\
\hline & Pre $(n=76)$ & Post ( $\mathrm{n}=76)$ & & \\
\hline Global health & $58.54(14.40)$ & $70.83(11.26)$ & $12.83(8.95$ to 16.71$)$ & $<.001$ \\
\hline Physical functioning & $75.25(15.88)$ & $85.35(13.16)$ & $10.88(6.80$ to 14.96$)$ & $<.001$ \\
\hline Role functioning & $66.45(26.45)$ & $70.83(24.36)$ & $5.26(-1.99$ to 12.52$)$ & .15 \\
\hline Emotional functioning & $59.06(19.31)$ & $64.04(19.82)$ & 5.59 (1.86 to 9.33$)$ & .004 \\
\hline Cognitive functioning & $62.5(22.11)$ & $80.26(21.38)$ & 17.98 (11.56 to 24.41$)$ & $<.001$ \\
\hline Social functioning & $66.88(23.94)$ & $86.62(20.00)$ & 20.17 (14.10 to 26.25$)$ & $<.001$ \\
\hline Fatigue & $42.5(23.64)$ & $23.68(15.95)$ & $-19.59(-26.09$ to -13.09$)$ & $<.001$ \\
\hline Nausea & $2.29(6.35)$ & $2.19(5.67)$ & $-0.22(-1.54$ to 1.10$)$ & .95 \\
\hline Pain & $44.58(26.22)$ & $38.6(20.59)$ & $-6.35(-12.64$ to -0.08$)$ & .047 \\
\hline Dyspnea & $27.92(25.13)$ & $12.72(19.60)$ & $-15.35(-21.24$ to -9.46$)$ & $<.001$ \\
\hline Insomnia & $46.25(36.16)$ & $35.09(32.61)$ & $-12.28(-20.70$ to -3.86$)$ & .005 \\
\hline Appetite loss & $9.58(15.18)$ & $7.46(15.00)$ & $-2.19(-6.38$ to 1.99$)$ & .30 \\
\hline Constipation & $21.67(28.11)$ & $19.74(29.40)$ & $-1.75(-8.78$ to 5.27$)$ & .62 \\
\hline Diarrhea & $10.83(19.68)$ & $12.72(18.83)$ & $1.31(-1.85$ to 4.47$)$ & .41 \\
\hline Financial difficulties & $19.17(28.94)$ & $16.67(24.65)$ & $-2.19(-5.99$ to 1.61$)$ & .25 \\
\hline
\end{tabular}

${ }^{\text {a } P a i r e d-s a m p l e ~} t$ test or Wilcoxon signed rank test as appropriate. Analyses were performed on only those patients that followed-up.

\section{Self-Efficacy and Motivation for Physical Activity and Accelerometry}

The results of the main pre-post analyses using the self-efficacy scale for PA and accelerometry are shown in Table 5. There were significant statistical differences after the experimental period with a moderate ES on the EAF scale as follows: daily PA $\left(t_{75}=5.369, P<.001, d=0.56\right)$, walking $\left(t_{75}=6.228, P<.001\right.$, $d=0.55)$, and total EAF score $\left(t_{75}=6.423, P<.001, d=0.67\right)$. For accelerometry, there were only significant differences in weekday moderate-to-vigorous physical activity (MVPA; $t_{75}=2.106, P=.04, d=0.26$ ), observing trend in global MVPA $\left(t_{75}=1.917, P=.06\right)$, weekday steps $\left(t_{75}=1.779, P=.08\right)$, and global steps $\left(t_{75}=1.647, P=.10\right)$. Therefore, after using BENECA mHealth, the users felt more motivated to increase the levels of PA in their daily lives. 
Table 5. Within-group pre-post effects on mean scores on the self-efficacy scale for physical activity (EAF) and accelerometry.

\begin{tabular}{|c|c|c|c|c|}
\hline \multirow[t]{2}{*}{ Variable } & \multicolumn{2}{|c|}{ Study group, mean (SD) } & \multirow[t]{2}{*}{ Mean difference $(95 \% \mathrm{CI})$} & \multirow[t]{2}{*}{$P$ value $^{\mathrm{a}}$} \\
\hline & $\operatorname{Pre}\left(n=76^{b}\right)$ & Post (n=76) & & \\
\hline \multicolumn{5}{|l|}{ EAF } \\
\hline Scheduled $\mathrm{PA}^{\mathrm{c}}$ & $81.70(33.08)$ & $87.71(19.22)$ & $6.08(-1.08,13.24)$ & .10 \\
\hline Daily live PA & $50.06(22.67)$ & $62.63(17.64)$ & $12.22(7.69,16.76)$ & $<.001$ \\
\hline Walking & $15.20(9.03)$ & $20.34(7.95)$ & $5.12(3.48,6.76)$ & $<.001$ \\
\hline Total EAF score & $146.96(53.36)$ & $184.61(48.52)$ & $36.99(25.52,48.46)$ & $<.001$ \\
\hline \multicolumn{5}{|l|}{ Accelerometry } \\
\hline MVPA $^{\mathrm{d}}$ weekday & $50.68(25.83)$ & $58.07(26.05)$ & $7.38(0.39,14.37)$ & .04 \\
\hline MVPA weekend & $41.77(24.55)$ & $42.77(21.51)$ & $0.99(-4.62,6.62)$ & .73 \\
\hline MVPA global & $48.14(24.31)$ & $53.69(21.85)$ & $5.55(-0.22,11.34)$ & .06 \\
\hline Steps weekday & $7488.97(3142.34)$ & $8268.41(3230.87)$ & $779.44(-94.35,1653.22)$ & .08 \\
\hline Steps weekend & $6218.50(3147.26)$ & $6316.87(2875.87)$ & $98.37(-678.14,874.88)$ & .80 \\
\hline Steps global & $7125.97(2935.94)$ & $7710.82(2672.78)$ & $584.85(-123.09,1292.78)$ & .10 \\
\hline
\end{tabular}

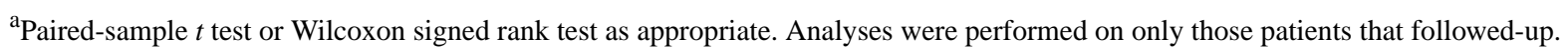

${ }^{\mathrm{b}}$ Accelerometry analyses was perform on 75 participants because there was one more dropout on preassessment (broken device).

${ }^{\mathrm{c}} \mathrm{PA}$ : physical activity.

${ }^{\mathrm{d}}$ MVPA: moderate-to-vigorous physical activity.

\section{Body Composition}

The results of the main pre-post analyses of the anthropometric variables are shown in Table 6. Statistically significant differences were observed after the experimental period with a moderate ES as follows: weight $\left(t_{75}=-5.050, P<.001, d=0.12\right)$ and $\operatorname{BMI}\left(t_{75}=-4.804, P<.001, d=0.12\right)$. In addition, a trend was observed in waist circumference $\left(t_{74}=-1.900, P=.06\right)$ and body fat $\left(t_{75}=-1.946, P=.06\right)$. No differences were observed for hip circumference $\left(t_{74}=-1.007, P=.32\right)$ and bone mineral density $\left(t_{75}=-1.019, P=.31\right)$. After 2 months of using BENECA mHealth, a reduction in users' body weight was observed, which could lead to a reduction in the hip circumference and percentage of body fat.

Table 6. Within-group pre-post differences on anthropometric and body composition variables.

\begin{tabular}{|c|c|c|c|c|}
\hline \multirow[t]{2}{*}{ Variable } & \multicolumn{2}{|c|}{ Study group, mean (SD) } & \multirow[t]{2}{*}{ Mean difference $(95 \% \mathrm{CI})$} & \multirow[t]{2}{*}{$P$ value $^{\mathrm{a}}$} \\
\hline & Pre $(n=76)$ & Post $(n=76)$ & & \\
\hline Weight (kg) & $73.09(11.14)$ & $71.67(10.90)$ & $-1.42(-1.97,-0.86)$ & $<.001$ \\
\hline $\mathrm{BMI}^{\mathrm{b}}\left(\mathrm{kg} / \mathrm{m}^{2}\right)$ & $29.11(4.78)$ & $28.51(4.73)$ & $-0.57(-0.81,-0.34)$ & $<.001$ \\
\hline Waist circumference $(\mathrm{cm})$ & $87.45(9.26)$ & $86.97(9.00)$ & $-0.84(-1.71,0.04)$ & .06 \\
\hline Hip circumference $(\mathrm{cm})$ & $107.94(14.23)$ & $107.71(13.11)$ & $-0.64(-1.93,0.63)$ & .32 \\
\hline Body fat $(\%)$ & $41.44(6.23)$ & $39.78(7.34)$ & $-1.57(-3.18,0.04)$ & .06 \\
\hline Bone mineral density $\left(\mathrm{g} / \mathrm{cm}^{2}\right)$ & $1.02(0.11)$ & $1.04(0.14)$ & $0.02(-0.02,0.05)$ & .31 \\
\hline
\end{tabular}

${ }^{\text {a } P a i r e d-s a m p l e ~} t$ test or Wilcoxon signed rank test as appropriate. Analyses were performed on only those patients that followed-up.

${ }^{\mathrm{b}} \mathrm{BMI}$ : body mass index.

\section{Discussion}

\section{Principal Results}

According to our initial hypothesis, after using BENECA mHealth for 8 weeks, the app was considered feasible by the breast cancer survivors in terms of use, adoption, and satisfaction, although the app quality score did not make it one of the best-rated apps. BENECA mHealth was associated with changes in the QoL of breast cancer survivors, as well as their self-perception of effectiveness and motivation for engaging in $\mathrm{PA}$ in their daily life.

\section{Comparison With Prior Work}

The adoption rate in this study was $69 \%$, and the usage rate was $73 \%$ to $76 \%$. These results can be explained by the technical characteristics of BENECA mHealth and its functionality, such 
as user-friendliness, the use of internationally accepted measures, and the visual feedback. The results of this study are comparable with those obtained by Melissant et al [13] for a supportive care app for breast cancer survivor, which had an adoption rate of $75 \%$ and usage rate of $75 \%$ to $84 \%$. Another study of a lifestyle intervention with a mobile app for endometrial and breast cancer survivors recorded a $75 \%$ usage rate [55]. However, Duman-Lubberding et al [11] obtained an adoption rate of $64 \%$ and a usage rate of $75 \%$ to $91 \%$ for a similar app for head and neck cancer survivors. The somewhat lower rate of use in our study for the latter may be due to how these data were obtained (ie, by the number of log-ins-objective measure-instead of the self-reported data of those studies-subjective measure). With regard to "app survival," we found that in a study by Springer et al [53] to test an mHealth app targeting healthy eating behavior in the general population, they obtained a survival rate less than $60 \%$ using the Kaplan-Meier survival curve. The higher survival rate in our study (over 70\%) can be explained by the type of population studied. In general, patients with some type of pathology will be more predisposed to be involved in this type of study than the general population [56]. In addition, experiencing cancer treatment may be a stimulus to use the app, as patients may feel the increased need to learn more about the treatment.

Taking into account the barriers perceived by the participants in the use of the app, the barriers reported by BENECA mHealth were in line with a recently published review on the adherence to online psychological interventions [57] as well as with those in a study by Melissant et al [13] with the Oncokompas app to monitor the QoL of breast cancer survivors (eg, "Oncokompas is too extensive"). The reported mean satisfaction score of the quality of BENECA mHealth, although it may seem not very high, is in line with a recently published study on the quality of 18 mobile apps for pain management using the same MARS quality scale [41]. In addition, the low scores in some sections can be explained by the barriers reported by the patients, such as the difficulties in inputting the intake that makes it very extensive to fill in the app. This barrier was also reported in another feasibility study on head and neck cancer patients [11]. Considering that the minimum score to be considered a best-rated app based on the MARS scale is 3.73 (according to a previous study [41]), BENECA mHealth can be regarded as an app with average ratings. BENECA is currently being improved in an attempt to address the reported barriers.

The benefits of PA for cancer patients have been amply demonstrated [58], although a recent meta-analysis (2013-2018) of distance-based PA behavioral change interventions for cancer survivors concluded that the effects of interventions on PA were small [18]. In addition, although efficacy cannot be discussed in a study such as this, according to the literature, a difference of 8 points between assessments of QoL measured with the EORT QLQ-C30 is the minimum clinically significant difference required to discuss the clinical relevance of the findings [59]. The QoL findings in this study reinforce these preceding conclusions and are consistent with the results of the EAF scale and those observed via accelerometry. Changes are observed in the participants with more motivation to do PA, and it seems that using BENECA mHealth is associated with changes that lead to a positive feedback chain that improves physical and emotional functioning. The significant differences in cognitive functioning can be explained by the actual use of the mobile device, as there is evidence of the cognitive benefits of using electronic devices [60]. Our findings are in agreement with those reported by Pope et al [20], who used a mobile app and social media for 10 weeks to improve the QoL of breast cancer survivors, with a sample size much smaller than ours. However, they differ from the conclusions of McCarroll et al [55], who assessed the effectiveness of a public mobile app (LoseIT) for dietetic intervention for 4 weeks in breast and endometrial cancer survivors. They did not find significant changes in the QoL of the patients. It is possible that the experimental period of 4 weeks and lack of stratification of the type of cancer could explain these differences, despite the use of a powerful questionnaire to assess QoL. Lastly, we only found statistically significant differences in the MVPA of the data obtained via accelerometry, although we observed an improvement in other variables after the use of BENECA mHealth. These results are consistent with those of a clinical trial published in 2018 that used smartwatches and social media PA behavioral change over a 10-week intervention to determine the health outcomes for breast cancer survivors, in which no significant differences in the accelerometry variables were observed [61].

Finally, one of the main challenges not only with cancer patients but with the general population is the maintenance and reduction of body weight $[5,62]$. Different studies of lifestyle interventions have shown beneficial results, such as the one by von Gurenigen et al [63] in which they evaluated the effectiveness of a face-to-face intervention on diets in obese patients with endometrial cancer, achieving a reduction of approximately $5 \%$. Similarly, McCarroll et al [55] achieved a reduction of approximately $6 \%$ from baseline weight. The literature indicates that a weight reduction of $5 \%$ is sufficient to reduce medical comorbidities [62]. In our study, an average weight loss of approximately $2 \%$ was achieved, which is below the recommendations. This may be because BENECA mHealth is not really a lifestyle intervention mobile app, but rather one that tries to incite behavioral change in users by monitoring their energy balance and making them aware of it. Therefore, we believe that the results obtained can be considered a first step, although future research should corroborate these results. The internal architecture of BENECA mHealth can also be extrapolated to suit patients with other types of cancer.

\section{Strengths and Limitations}

It is important to recognize some of the limitations of this study. The main one is its design. It is a nonrandomized, single-arm exploratory study; therefore, the results should be taken with caution. The ideal study would have been a randomized controlled trial (RCT); nevertheless, it was mandatory to develop a feasibility study for this sensitive population before carrying out an RCT. Moreover, due to the nature of the design of this study, the reported results must be confirmed in a larger RCT because the observed changes may not be attributable to the intervention. Secondly, BENECA was only developed for the Android operating system, but we are currently working on the next version of the BENECA app to solve this limitation. 
Thirdly, BENECA was designed to monitor energy balance and then propose recommendations based on international guidelines of clinical practice, systematic reviews, and meta-analysis to ensure the recommendations can be generalized. However, we believe that it is a good starting point, especially for very sedentary people. Finally, the generalization of results is limited due to the design of the study, the use of restrictive inclusion and exclusion criteria and the recruitment strategy (the participants were referred by their oncologists), which may involve a bias of the threat of regression to the mean. In addition, another added difficulty could refer to the use of the app by older people in southern Spain, who may not even have mobile phones adapted to the app. Therefore, future studies should be conducted with a larger sample size; a controlled and randomized clinical trial design comparing the use of BENECA with, for example, a face-to-face intervention; and including biomarker measurements such as those for inflammation or development/recurrence of breast cancer.

Despite these limitations, this study also has strengths. These include the wide range of ages of the participants, which makes it possible to generalize the results; the use of energy balance as a means of changing behavior, which has not been studied much; its ease of use; it has high adherence; and it has no adverse effect on the prior validation of BENECA mHealth [32], which guarantees its reliability.

\section{Conclusions}

BENECA mHealth can be considered feasible in a real clinical context and has been associated with behavioral changes in the lifestyles of breast cancer survivors, but it needs to be enhanced to improve user satisfaction with use and functionality. Having assumed that BENECA is usable and applicable in a real clinical context, as well as having the first data of its applicability and clinical efficacy, the next step will be to confirm these results through a larger study with a control group. In addition, efforts should focus on overcoming the barriers reported by the participants and developing a new version of BENECA mHealth in which these improvements will be implemented. Finally, future research could focus on its generalization for application to other oncological processes. This study highlights the importance of the use of mobile apps based on energy balance and how the QoL of breast cancer survivors can be improved via monitoring. The results of this study could garner support for the use of this type of strategy in the projected 29.5 million cancer patients in 2040 [64].

\section{Acknowledgments}

The study was funded by the Spanish Ministry of Economy and Competitiveness (Plan Estatal de I+D+I 2013-2016), Fondo de Investigación Sanitaria del Instituto de Salud Carlos III (PI14/01627), Fondos Estructurales de la Unión Europea (FEDER), and by the Spanish Ministry of Education (FPU14/01069 and FPU17/00939). This study occurred thanks to additional funding from the University of Granada, Plan Propio de Investigación 2016, Excellence Actions: Units of Excellence; Unit of Excellence on Exercise and Health (UCEES). This work was part of a PhD thesis conducted in the Clinical Medicine and Public Health Doctoral Studies of the University of Granada, Spain.

\section{Conflicts of Interest}

None declared.

\section{Multimedia Appendix 1}

Examples of feedback messages of the BENECA mHealth app.

[PDF File (Adobe PDF File), 34KB-Multimedia Appendix 1]

\section{References}

1. Ulrich CM, Himbert C, Holowatyj AN, Hursting SD. Energy balance and gastrointestinal cancer: risk, interventions, outcomes and mechanisms. Nat Rev Gastroenterol Hepatol 2018 Nov;15(11):683-698. [doi: 10.1038/s41575-018-0053-2] [Medline: $\underline{30158569}$ ]

2. Silvera SA, Jain M, Howe GR, Miller AB, Rohan TE. Energy balance and breast cancer risk: a prospective cohort study. Breast Cancer Res Treat 2006 May;97(1):97-106. [doi: 10.1007/s10549-005-9098-3] [Medline: 16319973]

3. Wang X, Liu W, Xie X. Energy imbalance and cancer: cause or consequence? IUBMB Life 2017 Dec;69(10):776-784 [FREE Full text] [doi: 10.1002/iub.1674] [Medline: 28858429]

4. Hill JO, Wyatt HR, Peters JC. The importance of energy balance. Eur Endocrinol 2013 Aug;9(2):111-115 [FREE Full text] [doi: 10.17925/EE.2013.09.02.111] [Medline: 29922364]

5. Romieu I, Dossus L, Barquera S, Blottière HM, Franks PW, Gunter M, IARC working group on Energy Balance and Obesity. Energy balance and obesity: what are the main drivers? Cancer Causes Control 2017 Dec;28(3):247-258 [FREE Full text] [doi: 10.1007/s10552-017-0869-z] [Medline: 28210884]

6. Lauby-Secretan B, Scoccianti C, Loomis D, Grosse Y, Bianchini F, Straif K, International Agency for Research on Cancer Handbook Working Group. Body fatness and cancer-viewpoint of the IARC Working Group. N Engl J Med 2016 Aug 25;375(8):794-798. [doi: 10.1056/NEJMsr1606602] [Medline: 27557308]

7. Courneya K. Exercise guidelines for cancer survivors: are fitness and quality-of-life benefits enough to change practice? Curr Oncol 2017 Feb 28;24(1):8. [doi: 10.3747/co.24.3545] [Medline: 28270718] 
8. Cannon C. Telehealth, mobile applications, and wearable devices are expanding cancer care beyond walls. Semin Oncol Nurs 2018 Dec;34(2):118-125. [doi: 10.1016/j.soncn.2018.03.002] [Medline: 29627143]

9. Aitken M, Kleinrock M, Simorellis A, Nass D. IQVIA. Global oncology trends 2018 URL: https://www.iqvia.com/-/media/ iqvia/pdfs/institute-reports/global-oncology-trends-2018.pdf

10. Berkowitz C, Zullig L, Koontz B, Smith S. Prescribing an ppp? Oncology providers' views on mobile health apps for cancer care. JCO Clin Cancer Inform 2017 Dec;1:1-7 [FREE Full text] [doi: 10.1200/CCI.17.00107] [Medline: 30657404]

11. Duman-Lubberding S, van Uden-Kraan CF, Jansen F, Witte B, van der Velden LA, Lacko M, et al. Feasibility of an eHealth application. Support Care Cancer 2016 May;24(5):2163-2171 [FREE Full text] [doi: 10.1007/s00520-015-3004-2] [Medline: $\underline{26563178}]$

12. van der Hout A, van Uden-Kraan CF, Witte B, Coupé VM, Jansen F, Leemans C, et al. Efficacy, cost-utility and reach of an eHealth self-management application 'Oncokompas' that helps cancer survivors to obtain optimal supportive care: study protocol for a randomised controlled trial. Trials 2017 Dec 22;18(1):228 [FREE Full text] [doi: 10.1186/s13063-017-1952-1] [Medline: 28532439]

13. Melissant H, Verdonck-de Leeuw IM, Lissenberg-Witte B, Konings I, Cuijpers P, Van Uden-Kraan CF. 'Oncokompas', a web-based self-management application to support patient activation and optimal supportive care: a feasibility study among breast cancer survivors. Acta Oncol 2018 Jul;57(7):924-934. [doi: 10.1080/0284186X.2018.1438654] [Medline: 29451059]

14. Ormel HL, van der Schoot GG, Westerink NL, Sluiter WJ, Gietema JA, Walenkamp AM. Self-monitoring physical activity with a smartphone application in cancer patients: a randomized feasibility study (SMART-trial). Support Care Cancer 2018 Nov;26(11):3915-3923 [FREE Full text] [doi: 10.1007/s00520-018-4263-5] [Medline: 29785635]

15. Hernandez Silva E, Lawler S, Langbecker D. The effectiveness of mHealth for self-management in improving pain, psychological distress, fatigue, and sleep in cancer survivors: a systematic review. J Cancer Surviv 2019 Feb;13(1):97-107. [doi: 10.1007/s11764-018-0730-8] [Medline: 30635865]

16. Seiler A, Klaas V, Tröster G, Fagundes C. eHealth and mHealth interventions in the treatment of fatigued cancer survivors: a systematic review and meta-analysis. Psychooncology 2017 Dec;26(9):1239-1253. [doi: 10.1002/pon.4489] [Medline: 28665554]

17. Lee H, Uhm K, Cheong I, Yoo J, Chung S, Park Y, et al. Patient satisfaction with mobile health (mHealth) application for exercise intervention in breast cancer survivors. J Med Syst 2018 Nov 06;42(12):254. [doi: 10.1007/s10916-018-1096-1] [Medline: 30402781]

18. Groen W, van Harten WH, Vallance J. Systematic review and meta-analysis of distance-based physical activity interventions for cancer survivors (2013-2018): We still haven't found what we're looking for. Cancer Treat Rev 2018 Sep;69:188-203. [doi: 10.1016/j.ctrv.2018.07.012] [Medline: 30077954]

19. Robertson MC, Tsai E, Lyons EJ, Srinivasan S, Swartz MC, Baum ML, et al. Mobile health physical activity intervention preferences in cancer survivors: a qualitative study. JMIR Mhealth Uhealth 2017 Jan 24;5(1):e3 [FREE Full text] [doi: 10.2196/mhealth.6970] [Medline: 28119278]

20. Pope Z, Lee JE, Zeng N, Lee HY, Gao Z. Feasibility of smartphone application and social media intervention on breast cancer survivors' health outcomes. Transl Behav Med 2018 Feb 17;9(1):22. [doi: 10.1093/tbm/iby002] [Medline: 29471477]

21. Egbring M, Far E, Roos M, Dietrich M, Brauchbar M, Kullak-Ublick G, et al. A mobile app to stabilize daily functional activity of breast cancer patients in collaboration with the physician: a randomized controlled clinical trial. J Med Internet Res 2016 Dec 06;18(9):e238 [FREE Full text] [doi: 10.2196/jmir.6414] [Medline: 27601354]

22. Cox S, Lane A, Volchenboum S. Use of wearable, mobile, and sensor technology in cancer clinical trials. JCO Clin Cancer Inform 2018 Dec;2:1-11 [FREE Full text] [doi: 10.1200/CCI.17.00147] [Medline: $\underline{\text { 30652590] }}$

23. Swendeman D, Comulada WS, Koussa M, Worthman CM, Estrin D, Rotheram-Borus MJ, et al. Longitudinal validity and reliability of brief smartphone self-monitoring of diet, stress, and physical activity in a diverse sample of mothers. JMIR Mhealth Uhealth 2018 Sep 21;6(9):e176 [FREE Full text] [doi: 10.2196/mhealth.9378] [Medline: $\underline{30249576}$ ]

24. Lee M, Lee H, Kim Y, Kim J, Cho M, Jang J, et al. Mobile app-based health promotion programs: a systematic review of the literature. Int J Environ Res Public Health 2018 Dec 13;15(12):2838. [doi: 10.3390/ijerph15122838]

25. Schoeppe S, Alley S, Rebar AL, Hayman M, Bray NA, Van Lippevelde W, et al. Apps to improve diet, physical activity and sedentary behaviour in children and adolescents: a review of quality, features and behaviour change techniques. Int $\mathbf{J}$ Behav Nutr Phys Act 2017 Jun 24;14(1):83 [FREE Full text] [doi: 10.1186/s12966-017-0538-3] [Medline: 28646889]

26. Dodd JM, Louise J, Cramp C, Grivell RM, Moran LJ, Deussen AR. Evaluation of a smartphone nutrition and physical activity application to provide lifestyle advice to pregnant women: The SNAPP randomised trial. Matern Child Nutr 2017 Aug 24;14(1):e12502. [doi: 10.1111/mcn.12502]

27. Paulsen MM, Hagen ML, Frøyen MH, Foss-Pedersen RJ, Bergsager D, Tangvik RJ, et al. A dietary assessment app for hospitalized patients at nutritional risk: development and evaluation of the MyFood app. JMIR Mhealth Uhealth 2018 Sep 07;6(9):e175. [doi: 10.2196/mhealth.9953]

28. Thijs I, Fresiello L, Oosterlinck W, Sinnaeve P, Rega F. Assessment of physical activity by wearable technology during rehabilitation after cardiac surgery: explorative prospective monocentric observational cohort study. JMIR Mhealth Uhealth 2019 Jan 31;7(1):e9865 [FREE Full text] [doi: 10.2196/mhealth.9865] [Medline: 30702433] 
29. Wu X, Guo X, Zhang Z. The efficacy of mobile phone apps for lifestyle modification in diabetes: systematic review and meta-analysis. JMIR Mhealth Uhealth 2019 Jan 15;7(1):e12297 [FREE Full text] [doi: 10.2196/12297] [Medline: 30664494]

30. Feehan LM, Geldman J, Sayre EC, Park C, Ezzat AM, Yoo JY, et al. Accuracy of Fitbit devices: systematic review and narrative syntheses of quantitative data. JMIR Mhealth Uhealth 2018 Aug 09;6(8):e10527 [FREE Full text] [doi: 10.2196/10527] [Medline: 30093371$]$

31. Lozano-Lozano M, Moral-Munoz JA, Galiano-Castillo N, Martín-Martín L, Fernández-Lao C, Arroyo-Morales M, et al. Designing BENECA m-Health app, a mobile health application to monitor diet and physical activity in cancer survivors. In: Rojas I, Joya G, Catala A, editors. Advances in Computational Intelligence. IWANN 2017. Lecture Notes in Computer Science. Cham, Switzerland: Springer; 2017:63-70.

32. Lozano-Lozano M, Galiano-Castillo N, Martín-Martín L, Pace-Bedetti N, Fernández-Lao C, Arroyo-Morales M, et al. Monitoring energy balance in breast cancer survivors using a mobile app: reliability study. JMIR Mhealth Uhealth 2018 Mar 27;6(3):e67 [FREE Full text] [doi: 10.2196/mhealth.9669] [Medline: 29588273]

33. Finne E, Glausch M, Exner A, Sauzet O, Stölzel F, Seidel N. Behavior change techniques for increasing physical activity in cancer survivors: a systematic review and meta-analysis of randomized controlled trials. Cancer Manag Res 2018 Oct;10:5125-5143 [FREE Full text] [doi: 10.2147/CMAR.S170064] [Medline: 30464612]

34. Hillier FC, Batterham AM, Crooks S, Moore HJ, Summerbell CD. The development and evaluation of a novel Internet-based computer program to assess previous-day dietary and physical activity behaviours in adults: the Synchronised Nutrition and Activity Program for Adults (SNAPA ${ }^{\mathrm{TM}}$ ). Br J Nutr 2012 Apr;107(8):1221-1231. [doi: 10.1017/S0007114511004090] [Medline: 21861942]

35. Government of Spain. Law 14/2007, of July 3, on Biomedical Research. Inter-University Chair in Law and the Human Genome: Off Bull State, No 159, BOE-A-2007-12945 (Jun 2) 2011:1-48 [FREE Full text]

36. Lozano-Lozano M, Martín-Martín L, Galiano-Castillo N, Álvarez-Salvago F, Cantarero-Villanueva I, Fernández-Lao C, et al. Integral strategy to supportive care in breast cancer survivors through occupational therapy and a m-health system: design of a randomized clinical trial. BMC Med Inform Decis Mak 2016 Nov 25;16(1):150 [FREE Full text] [doi: 10.1186/s12911-016-0394-0] [Medline: 27887610]

37. Schmitz K, Courneya K, Matthews C, Demark-Wahnefried W, Galvão DA, Pinto B, American College of Sports Medicine. American College of Sports Medicine roundtable on exercise guidelines for cancer survivors. Med Sci Sports Exerc 2010 Jul;42(7):1409-1426. [doi: 10.1249/MSS.0b013e3181e0c112] [Medline: 20559064]

38. Kushi L, Doyle C, McCullough M, Rock C, Demark-Wahnefried W, Bandera EV, American Cancer Society 2010 Nutrition and Physical Activity Guidelines Advisory Committee. American Cancer Society Guidelines on nutrition and physical activity for cancer prevention: reducing the risk of cancer with healthy food choices and physical activity. CA Cancer J Clin 2012;62(1):30-67 [FREE Full text] [doi: 10.3322/caac.20140] [Medline: 22237782]

39. Vollmer DD, Fair K, Hong YA, Beaudoin CE, Pulczinski J, Ory MG. Apps seeking theories: results of a study on the use of health behavior change theories in cancer survivorship mobile apps. JMIR Mhealth Uhealth 2015;3(1):e31 [FREE Full text] [doi: 10.2196/mhealth.3861] [Medline: 25830810]

40. Cnossen I, van Uden-Kraan CF, Rinkel R, Aalders I, de Goede CJ, de Bree R, et al. Multimodal guided self-help exercise program to prevent speech, swallowing, and shoulder problems among head and neck cancer patients: a feasibility study. J Med Internet Res 2014 Mar 06;16(3):e74 [FREE Full text] [doi: 10.2196/jmir.2990] [Medline: 24610383]

41. Salazar A, de Sola H, Failde I, Moral-Munoz JA. Measuring the quality of mobile apps for the management of pain: systematic search and evaluation using the mobile app rating scale. JMIR Mhealth Uhealth 2018 Oct 25;6(10):e10718 [FREE Full text] [doi: 10.2196/10718] [Medline: $\underline{30361196}$ ]

42. Eysenbach G. The law of attrition. J Med Internet Res 2005 Mar 31;7(1):e11 [FREE Full text] [doi: 10.2196/jmir.7.1.e11] [Medline: 15829473$]$

43. Stoyanov SR, Hides L, Kavanagh DJ, Zelenko O, Tjondronegoro D, Mani M. Mobile app rating scale: a new tool for assessing the quality of health mobile apps. JMIR Mhealth Uhealth 2015;3(1):e27 [FREE Full text] [doi: 10.2196/mhealth.3422] [Medline: 25760773]

44. Krol M, de Boer D, Delnoij D, Rademakers JJ. The Net Promoter Score--an asset to patient experience surveys? Health Expect 2015 Dec;18(6):3099-3109 [FREE Full text] [doi: 10.1111/hex.12297] [Medline: 25345554]

45. Koladycz R, Fernandez G, Gray K, Marriott H. The Net Promoter Score (NPS) for insight into client experiences in sexual and reproductive health clinics. Glob Health Sci Pract 2018 Dec 03;6(3):413-424 [FREE Full text] [doi: 10.9745/GHSP-D-18-00068] [Medline: 30072372]

46. Pope C, Ziebland S, Mays N. Qualitative research in health care. Analysing qualitative data. BMJ 2000 Jan 08;320(7227):114-116 [FREE Full text] [doi: 10.1136/bmj.320.7227.114] [Medline: 10625273]

47. Aaronson N, Ahmedzai S, Bergman B, Bullinger M, Cull A, Duez N, et al. The European Organization for Research and Treatment of Cancer QLQ-C30: a quality-of-life instrument for use in international clinical trials in oncology. J Natl Cancer Inst 1993 Mar 03;85(5):365-376. [doi: 10.1093/jnci/85.5.365] [Medline: $\underline{8433390]}$

48. Nolte S, Liegl G, Petersen MA, Aaronson NK, Costantini A, Fayers PM, EORTC Quality of Life Group. General population normative data for the EORTC QLQ-C30 health-related quality of life questionnaire based on 15,386 persons across 13 
European countries, Canada and the Unites States. Eur J Cancer 2019 Jan;107:153-163 [FREE Full text] [doi: 10.1016/j.ejca.2018.11.024] [Medline: 30576971]

49. Fernández Cabrera T, Medina Anzano S, Herrera Sánchez IM, Rueda Méndez S, Fernández Del Olmo A. [Construction and validation of a self-efficacy scale for physical activity]. Rev Esp Salud Publica 2011 Aug;85(4):405-417 [FREE Full text] [doi: 10.1590/S1135-57272011000400009] [Medline: 22392471]

50. Carbonell-Baeza A, Ruiz J, Aparicio V, Ortega F, Munguía-Izquierdo D, Alvarez-Gallardo IC, et al. Land- and water-based exercise intervention in women with fibromyalgia: the al-Andalus physical activity randomised controlled trial. BMC Musculoskelet Disord 2012 Feb 15;13:18 [FREE Full text] [doi: 10.1186/1471-2474-13-18] [Medline: 22336292]

51. Greenspan S, Vujevich K, Brufsky A, Lembersky B, van Londen GJ, Jankowitz R, et al. Prevention of bone loss with risedronate in breast cancer survivors: a randomized, controlled clinical trial. Osteoporos Int 2015 Jun;26(6):1857-1864 [FREE Full text] [doi: 10.1007/s00198-015-3100-7] [Medline: 25792492]

52. Leahy S, Toomey C, McCreesh K, O'Neill C, Jakeman P. Ultrasound measurement of subcutaneous adipose tissue thickness accurately predicts total and segmental body fat of young adults. Ultrasound Med Biol 2012 Jan;38(1):28-34. [doi: 10.1016/j.ultrasmedbio.2011.10.011] [Medline: 22104525]

53. Springer A, Venkatakrishnan A, Mohan S, Nelson L, Silva M, Pirolli P. Leveraging self-affirmation to improve behavior change: a mobile health app experiment. JMIR Mhealth Uhealth 2018 Jul 19;6(7):e157. [doi: 10.2196/mhealth.9151]

54. Schafer J. Multiple imputation: a primer. Stat Methods Med Res 1999 Mar;8(1):3-15. [doi: 10.1177/096228029900800102] [Medline: 10347857]

55. McCarroll M, Armbruster S, Pohle-Krauza R, Lyzen A, Min S, Nash D, et al. Feasibility of a lifestyle intervention for overweight/obese endometrial and breast cancer survivors using an interactive mobile application. Gynecol Oncol 2015 Jun;137(3):508-515. [doi: 10.1016/j.ygyno.2014.12.025] [Medline: 25681782]

56. Anderson A, Borfitz D, Getz K. Global public attitudes about clinical research and patient experiences with clinical trials. JAMA Netw Open 2018 Oct 05;1(6):e182969. [doi: 10.1001/jamanetworkopen.2018.2969]

57. Beatty L, Binnion C. A systematic review of predictors of, and reasons for, adherence to online psychological interventions. Int J Behav Med 2016 Dec;23(6):776-794. [doi: 10.1007/s12529-016-9556-9] [Medline: 26957109]

58. Segal R, Zwaal C, Green E, Tomasone J, Loblaw A, Petrella T, Exercise for People with Cancer Guideline Development Group. Exercise for people with cancer: a clinical practice guideline. Curr Oncol 2017 Feb;24(1):40-46 [FREE Full text] [doi: 10.3747/co.24.3376] [Medline: 28270724]

59. Kvam A, Fayers P, Wisloff F. Responsiveness and minimal important score differences in quality-of-life questionnaires: a comparison of the EORTC QLQ-C30 cancer-specific questionnaire to the generic utility questionnaires EQ-5D and 15D in patients with multiple myeloma. Eur J Haematol 2011 Oct;87(4):330-337. [doi: 10.1111/j.1600-0609.2011.01665.x] [Medline: 21668504]

60. Wilmer H, Sherman L, Chein J. Smartphones and cognition: a review of research exploring the links between mobile technology habits and cognitive functioning. Front Psychol 2017;8:605 [FREE Full text] [doi: 10.3389/fpsyg.2017.00605] [Medline: 28487665]

61. Pope Z, Zeng N, Zhang R, Lee H, Gao Z. Effectiveness of combined smartwatch and social media intervention on breast cancer survivor health outcomes: a 10-week pilot randomized trial. J Clin Med 2018 Jun 07;7(6):140. [doi: 10.3390/jcm7060140]

62. Appel L. UpToDate. Overweight, obesity, and weight reduction in hypertension Internet URL: https://www.uptodate.com/ contents/overweight-obesity-and-weight-reduction-in-hypertension\#H7 [accessed 2019-03-06]

63. von Gruenigen VE, Waggoner S, Frasure H, Kavanagh M, Janata J, Rose P, et al. Lifestyle challenges in endometrial cancer survivorship. Obstet Gynecol 2011 Jan;117(1):93-100. [doi: 10.1097/AOG.0b013e31820205b3] [Medline: 21173649]

64. International Agency for Research on Cancer. Global Cancer Observatory URL: https://gco.iarc.fr

\author{
Abbreviations \\ BMI: body mass index \\ EAF: self-efficacy scale for physical activity (Spanish) \\ Core 30 \\ ES: effect size \\ MARS: Mobile App Rating Scale \\ MVPA: moderate-to-vigorous physical activity \\ NPS: Net Promoter Score \\ PA: physical activity \\ QoL: quality of life \\ RCT: randomized controlled trial
}

EORT QLQ-C30: European Organization for Research and Treatment of Cancer Quality of Life Questionnaire 
Edited by G Eysenbach; submitted 26.03.19; peer-reviewed by F Artacho-Cordon, M Robertson; comments to author 18.04.19; revised version received 13.05.19; accepted 16.05.19; published 25.06.19

Please cite as:

Lozano-Lozano M, Cantarero-Villanueva I, Martin-Martin L, Galiano-Castillo N, Sanchez MJ, Fernández-Lao C, Postigo-Martin P, Arroyo-Morales $M$

A Mobile System to Improve Quality of Life Via Energy Balance in Breast Cancer Survivors (BENECA mHealth): Prospective

Test-Retest Quasiexperimental Feasibility Study

JMIR Mhealth Uhealth 2019;7(6):e14136

URL: http://mhealth.jmir.org/2019/6/e14136/

doi: 10.2196/14136

PMID: 31237570

CMario Lozano-Lozano, Irene Cantarero-Villanueva, Lydia Martin-Martin, Noelia Galiano-Castillo, Maria-José Sanchez, Carolina Fernández-Lao, Paula Postigo-Martin, Manuel Arroyo-Morales. Originally published in JMIR Mhealth and Uhealth (http://mhealth.jmir.org), 25.06.2019. This is an open-access article distributed under the terms of the Creative Commons Attribution License (https://creativecommons.org/licenses/by/4.0/), which permits unrestricted use, distribution, and reproduction in any medium, provided the original work, first published in JMIR mhealth and uhealth, is properly cited. The complete bibliographic information, a link to the original publication on http://mhealth.jmir.org/, as well as this copyright and license information must be included. 